\title{
Empirical model of equatorial electrojet based on ground-based magnetometer data during solar minimum in fall
}

\author{
Nurul Shazana Abdul Hamid ${ }^{1 *}$, Huixin Liu ${ }^{2,3}$, Teiji Uozumi ${ }^{3}$ and Akimasa Yoshikawa ${ }^{2,3}$
}

\begin{abstract}
In this study, we constructed an empirical model of the equatorial electrojet (EEJ), including local time and longitudinal dependence, based on simultaneous data from 12 magnetometer stations located in six longitude sectors. An analysis was carried out using the equatorial electrojet index, EUEL, calculated from the geomagnetic northward $\mathrm{H}$ component. The magnetic EEJ strength is calculated as the difference between the normalized EUEL index of the magnetic dip equator station and the normalized EUEL index of the off-dip equator station located beyond the EEJ band. Analysis showed that this current is always strongest in the South American sector, regardless of local time (LT), and weakest in the Indian sector during 0900 and $1000 \mathrm{LT}$, but shifted to the African sector during 1100 to 1400 LT. These longitude variations of EEJ roughly follow variations of the inversed main field strength along the dip equator, except for the Indian and Southeast Asian sectors. The result showed that the EEJ component derived from the model exhibits a similar pattern with measured EEJ from ground data during noontime, mainly before 1300 LT.
\end{abstract}

Keywords: Equatorial electrojet, Empirical model, Local time dependence, Longitudinal dependence

\section{Introduction}

The equatorial electrojet current has always been conceived as a phenomenon confined to a narrow area around $\pm 3^{\circ}$ of the dip equator. This current is an intense electric current, flowing eastward in the dayside of an equatorial $\mathrm{E}$ region that is about $600 \mathrm{~km}$ wide. The primary reason for this intense current density is the geomagnetic field geometry, which exhibits exactly horizontal lines of force at these latitudes. On the other hand, solar quiet $(\mathrm{Sq})$ is a global current system consisting of two large vortices of electric currents in the dayside ionosphere, one in each hemisphere, counterclockwise in the Northern Hemisphere, and clockwise in the Southern Hemisphere. This current is driven by solar extreme ultraviolet (EUV) radiation, which not only produces the ionization in the $\mathrm{E}$ region but also heats the atmosphere and causes the wind. Both currents overlap at the dip equator to give the total current and significantly affect

\footnotetext{
* Correspondence: shazana.ukm@gmail.com

${ }^{1}$ School of Applied Physics, Faculty of Science and Technology, Universiti

Kebangsaan Malaysia, 43600 UKM Bangi, Selangor, Malaysia

Full list of author information is available at the end of the article
}

the geomagnetic data measured in the area (Forbes 1981; Stening 1995; Onwumechili 1997). Previous study by Hamid et al. (2014) has successfully separated equatorial electrojet (EEJ) and Sq at the dip equator observed from three longitude sectors: South America, India, and Southeast Asia. The normalization approach suggested by them gives an opportunity to construct an EEJ empirical model based on observational data, mainly from ground-based magnetometers, regardless of the effect of EEJ and Sq latitudinal variations.

There have been previous attempts in constructing EEJ models, both theoretically and empirically. Most theoretical approaches have assumed various current distributions and analyzed the resulting magnetic effects (Chapman 1951; Fambitakoye and Mayaud 1976). On the other hand, the empirical model of Onwumechili and Ezema (1992) is based on POGO satellite data, which provide measurement of several important parameters of EEJ, such as mean peakcurrent intensity. However, it does not offer a longitudinal profile of EEJ. The longitudinal variation of EEJ has been reported by several studies, such as
Springer

(c) 2015 Hamid et al. Open Access This article is distributed under the terms of the Creative Commons Attribution 4.0 International License (http://creativecommons.org/licenses/by/4.0/), which permits unrestricted use, distribution, and reproduction in any medium, provided you give appropriate credit to the original author(s) and the source, provide a link to the Creative Commons license, and indicate if changes were made. 
Doumouya et al. (2003), Alken and Maus (2007), Shume et al. (2010), and Chandrasekhar et al. (2014). Among these, a comprehensive study is given by Doumouya et al. (2003) in their empirical model of EEJ magnetic signature based on ground magnetic data recorded from a single station at six longitude sectors. However, due to the absence of an off-dip equator station, they did not eliminate the Sq contribution to geomagnetic data. The same problem was faced by Doumouya and Cohen (2004). In this study, we used the same method proposed by Doumouya et al. (2003), with some modifications. First, we eliminated the Sq contribution at the dip equator by using a two-station method. Second, we considered latitudinal variation of the $\mathrm{Sq}$ and EEJ magnetic signature by normalizing the observation data to the dip equator. Both aspects were previously unattainable with ground-based data. The output from the present model was compared with the study using satellite data proposed by Alken and Maus (2007). Additionally, we validated the model output by comparing it with the observation data collected during the same period of the following year.

\section{Data and method of analysis}

In this study, a simple empirical model of the EEJ magnetic signature was developed using simultaneous normalized data from 12 stations, as shown in Fig. 1. The stations were grouped into six pairs, one in the South American sector, two in the African sector (east and west), one in the Indian sector, and two in the Southeast Asian sector (east and west). The locations of each station are presented in Table 1 . The observation data used were equatorial electrojet index, EUEL (Uozumi et al. 2008), derived from the northward geomagnetic H component measured by a ground-based magnetometer system, mainly by the Magnetic Data Acquisition System (MAGDAS) (Yumoto and the MAGDAS Group 2007). This index represents local magnetic variation after global magnetic variation, represented by the EDst index, was removed from the $\mathrm{H}$ component data. Therefore,
Table 1 Geomagnetic and geographic coordinates of stations used in this study

\begin{tabular}{|c|c|c|c|c|c|}
\hline \multirow[t]{2}{*}{ Region } & \multirow{2}{*}{$\begin{array}{l}\text { Station name } \\
\text { (code) }\end{array}$} & \multicolumn{2}{|c|}{ Geographic } & \multicolumn{2}{|c|}{ Geomagnetic } \\
\hline & & Lat. $\left(^{\circ}\right)$ & Lon. $\left({ }^{\circ}\right)$ & Lat. $\left(^{\circ}\right)$ & Lon. $\left(^{\circ}\right)$ \\
\hline \multirow[t]{2}{*}{ South America } & Ancon (ANC) & -11.77 & -77.15 & 0.77 & 354.33 \\
\hline & Fuquene (FUQ) & 5.40 & -73.73 & 15.72 & 357.99 \\
\hline \multirow[t]{4}{*}{ African } & Ilorin (ILR) & 8.50 & 4.68 & -1.82 & 76.80 \\
\hline & Tamanrasset (TAM) & 22.8 & 5.5 & 25.4 & 80.6 \\
\hline & Adis Ababa (AAB) & 9.04 & 38.77 & 0.18 & 110.47 \\
\hline & Nairobi (NAB) & -1.16 & 36.48 & -10.65 & 108.18 \\
\hline \multirow[t]{2}{*}{ India } & Tirunelveli (TIR) & 8.70 & 77.80 & 0.21 & 149.30 \\
\hline & Alibag (ABG) & 18.62 & 72.87 & 10.36 & 146.54 \\
\hline \multirow[t]{4}{*}{ Southeast Asia } & Langkawi (LKW) & 6.30 & 99.78 & -2.32 & 171.29 \\
\hline & Kototabang (KTB) & -0.20 & 100.32 & -10.63 & 171.93 \\
\hline & Davao (DAV) & 7.00 & 125.40 & -1.02 & 196.54 \\
\hline & Muntinlupa (MUT) & 14.37 & 121.02 & 6.79 & 192.25 \\
\hline
\end{tabular}

the EUEL index is a local index where its variation is independent of global disturbances in the equatorial region, particularly from storm sudden commencement (SSC) and ring currents, and parts of magnetospheric origin disturbances. Details on the EUEL index can be found in Hamid et al. (2013). The simultaneous data were obtained from September 16 to 30,2009 , which represents the period of solar minimum in fall. The analysis was carried out using the maximum EUEL index during noontime to avoid morning and evening local effects such as the counter-electrojet effect.

As the stations are not located exactly at $0^{\circ}$ dip latitude, we utilized the latest comprehensive model (CM), CM4 global current model (Sabaka et al. 2004), using ionospheric field components, to normalize observation data to the dip equator. This approach, introduced by Hamid et al. (2014), helps to minimize uncertainties due to the latitudinal variation of both EEJ and Sq currents. The normalized Sq at the dip equator [EUEL $\left(0^{\circ}\right)$ ] is obtained from the normalization of EUEL data of stations

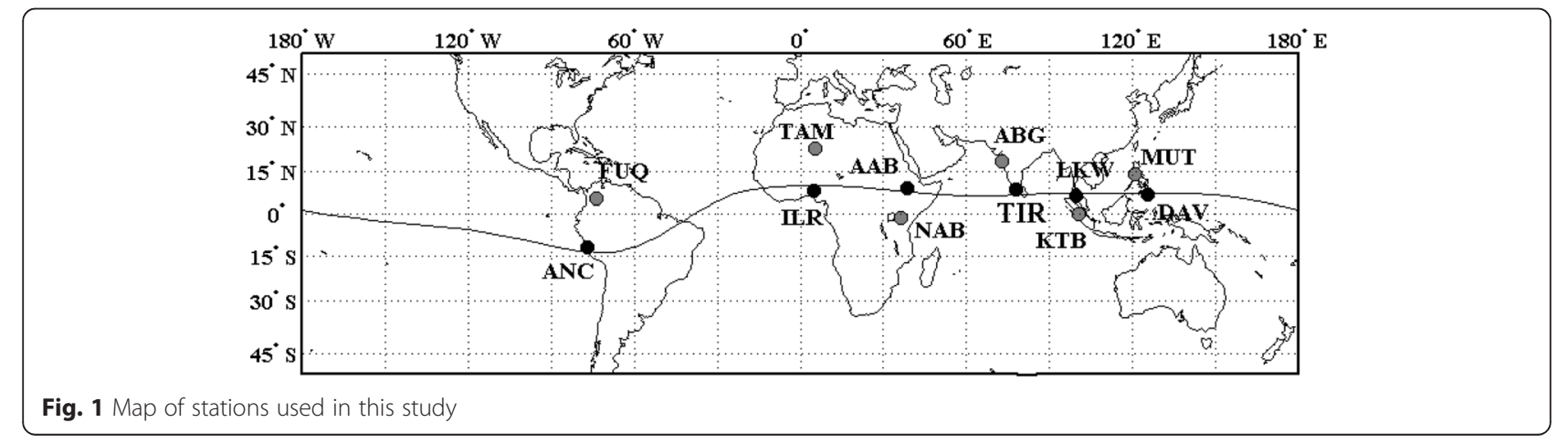


at the off-dip equator [EUEL $\left(\theta^{\circ}\right)$ ], using the following formula:

$$
\operatorname{EUEL}\left(0^{\circ}\right)=\frac{\mathrm{CM}_{4}\left(0^{\circ}\right)}{\mathrm{CM}_{4}\left(\theta^{\circ}\right)} \operatorname{EUEL}\left(\theta^{\circ}\right) .
$$

Readings of $\mathrm{CM}_{4}\left(0^{\circ}\right)$ and $\mathrm{CM}_{4}\left(\theta^{\circ}\right)$ were acquired from the latitudinal profiles of Sq represented by the polynomial fitting of the CM4 model values after the region of $\pm 3^{\circ}$ around the dip equator was masked to avoid the influence of the CM4 EEJ signature. On the other hand, the total current at the dip equator is obtained from the normalization of EUEL data observed at the station near the dip equator directly, using the CM4 model profile and the same formula. Figure 2 illustrates an example of TIR-ABG pair in the Indian sector where the normalized data are indicated by the diamond symbol. The EEJ current was then calculated as the difference between the normalized total current at the dip equator and the normalized $\mathrm{Sq}$ at the dip equator:

$$
\mathrm{EEJ}=\mathrm{EUEL}_{\mathrm{total}}\left(0^{\circ}\right)-\mathrm{EUEL}_{\mathrm{Sq}}\left(0^{\circ}\right) .
$$

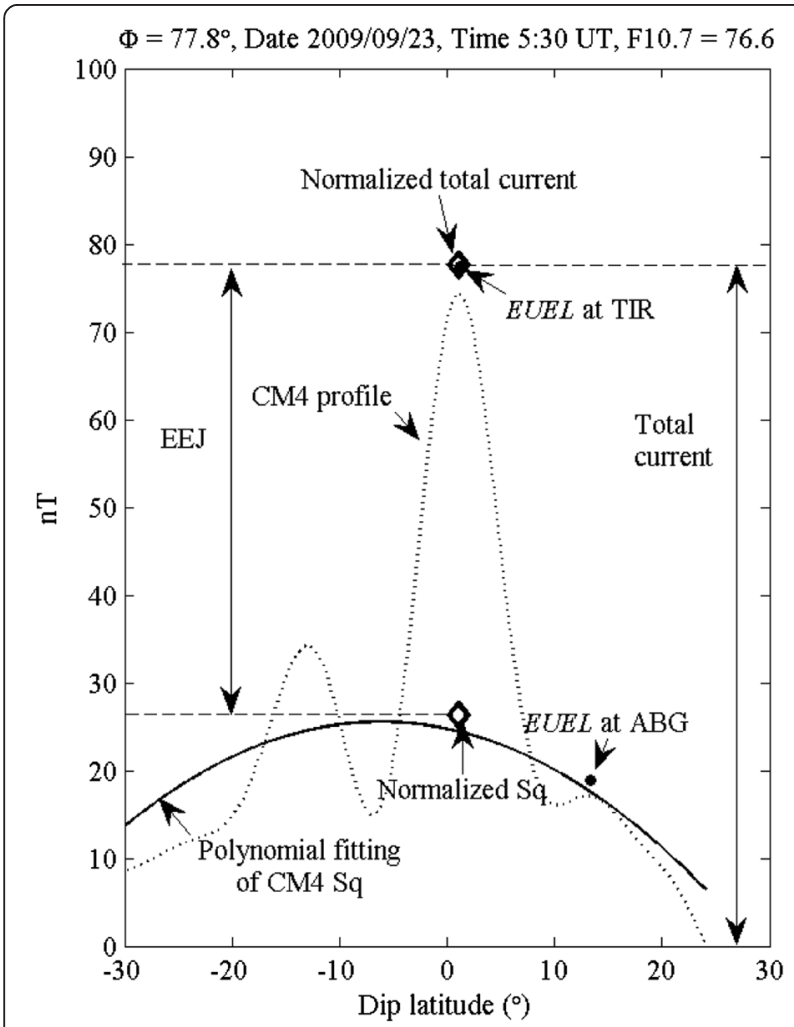

Fig. 2 Example of a normalization of the EUEL index at the Indian sector. The black dots indicate the EUEL at TIR and ABG stations while the normalized readings of these indices are indicated by open diamonds. The EEJ is calculated by subtracting the normalized Sq from the normalized total current
The same procedures were applied to all observation EUEL data from all station pairs. Figure 3 shows the plot of the mean EEJ magnetic signature around noontime from 0900 local time (LT) to $1500 \mathrm{LT}$, calculated from the normalized data of all station pairs.

\section{EEJ empirical model}

The EEJ magnetic signature calculated from the observation data was then used to construct the EEJ empirical model. Two functions considered are local time and longitude dependence. The time-and longitude-varying current intensity, $I(t, \lambda)$, where the unit is in $\mathrm{A} / \mathrm{m}$, is given by

$$
I(t, \lambda)=I_{11}(\lambda) \exp \left(-\frac{(t-T)^{2}}{t_{\mathrm{m}}^{2}}\right) .
$$

In this model, $t_{\mathrm{m}}$ is a fitting parameter that controls the time window of the Gaussian-like shape with the average value being $4 \mathrm{~h}$ (Doumouya et al. 2003). On the other hand, both $T$ (the local time of maximum EEJ) and the longitudinal function of EEJ, $I_{11}(\lambda)$, are determined from the observation data. From the data analysis, it is shown that on average, $T$ is equal to 1100 LT (see Fig. 3).

Figure 4 shows the mean values of EEJ magnetic signature along the dip equator at six longitude sectors for local time 0900 LT to 1500 LT. Dash lines represent the spline interpolations that fit the normalized observation data. It can be seen that the EEJ magnetic component is always strongest in the South American sector, regardless of local time. However, the EEJ component is found to be weakest in the Indian sector during 0900 and 1000 LT but shifted to the African sector during 1100 to 1400 LT. Based on the local time dependence discussed earlier, the longitudinal profile of EEJ (in $\mathrm{nT}$ ) was chosen to be expressed by the numerical spline function fitting the mean EEJ at $1100 \mathrm{LT}, \mathrm{EEJ}_{11}(\lambda)$, with about $30^{\circ}$ of interval between 13 control points, $n$, along the dip equator,

$$
\begin{aligned}
\operatorname{EEJ}_{11}(\lambda)= & a_{i}\left(\lambda-\lambda_{i}\right)^{3}+b_{i}\left(\lambda-\lambda_{i}\right)^{2}+c_{i}\left(\lambda-\lambda_{i}\right) \\
& +d_{i}
\end{aligned}
$$

where the coefficients, $a_{i}, b_{i}, c_{i}$, and $d_{i}$, are the spline coefficients with $i=1,2,3, . ., n-1$. The control points $\lambda_{i}$ used here are composed of the longitude of the dip equator stations and the longitudes of the added or subtracted $360^{\circ}$ from longitudes of these stations. Figure 5 shows this spline function that fits the EEJ magnetic data. According to Doumouya et al. (2003), the EEJ strength is best expressed by the current intensity at the EEJ center, which is related to 


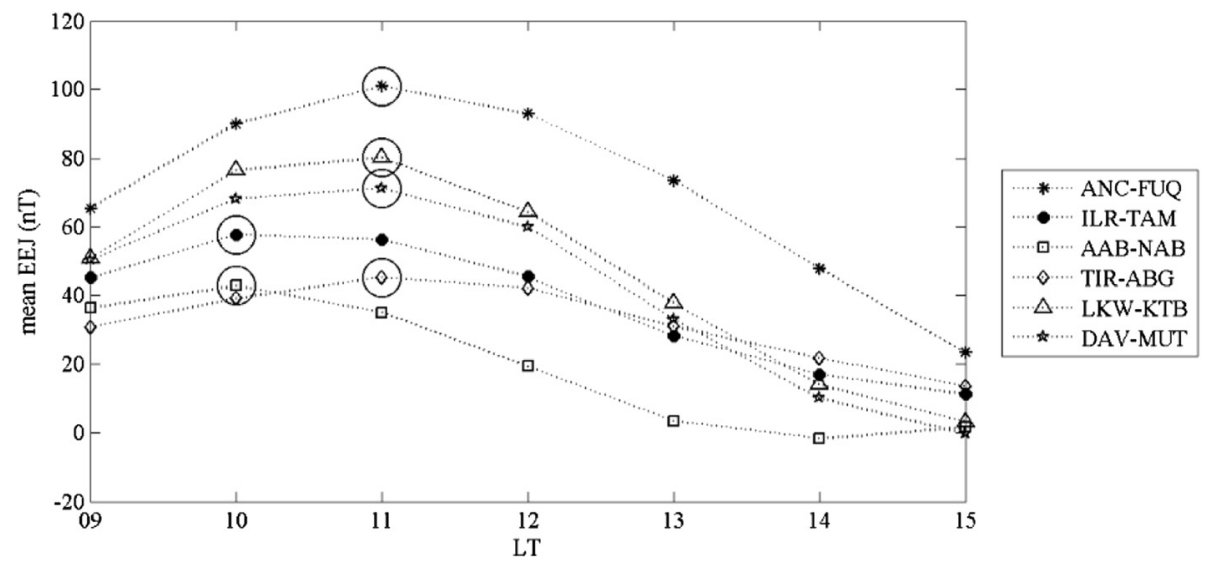

Fig. 3 Mean EEJ during September 16-30 from 0900 LT to 1500 LT calculated from all station pairs. Circles indicate the maximum mean EEJ of each pair

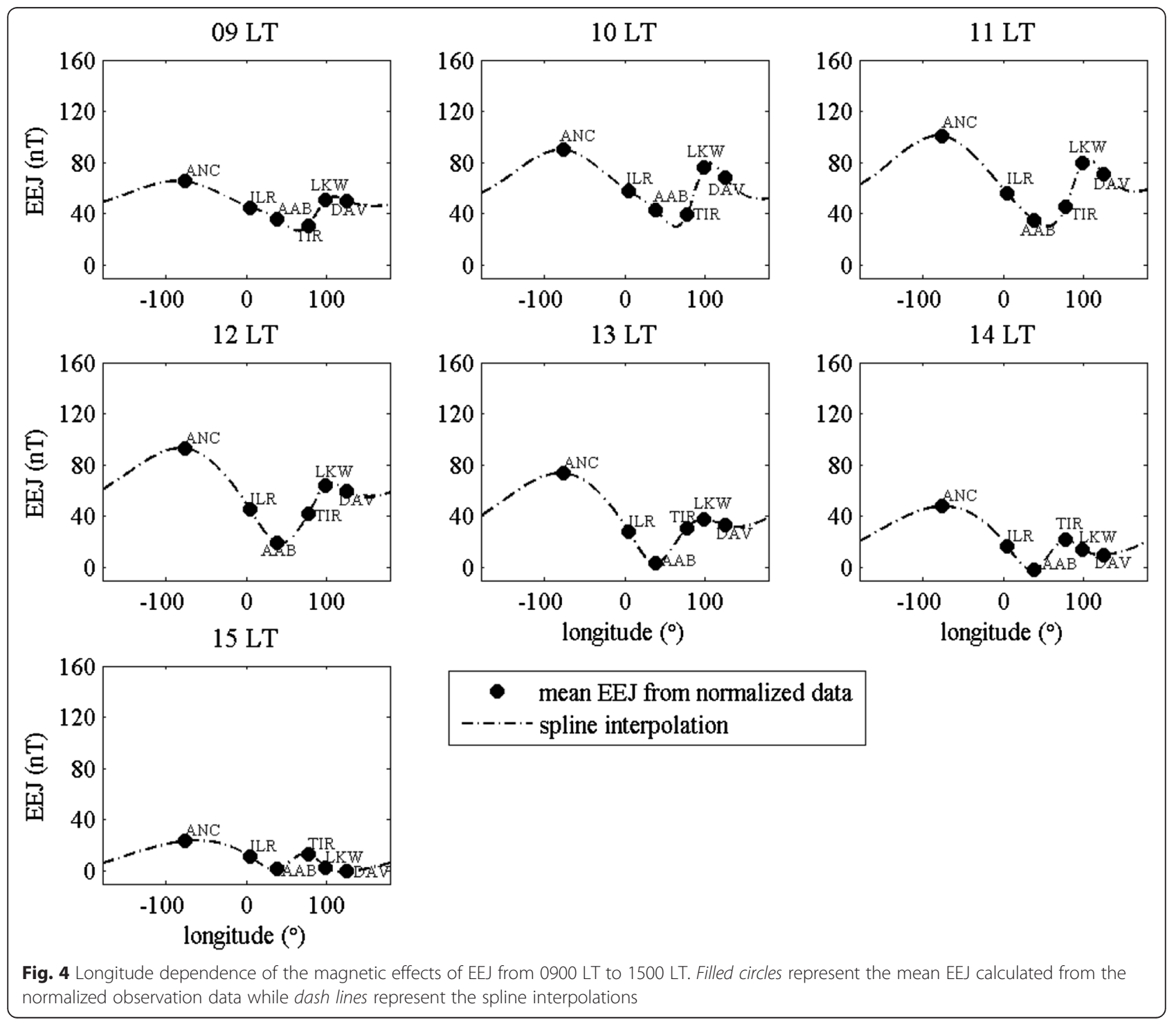




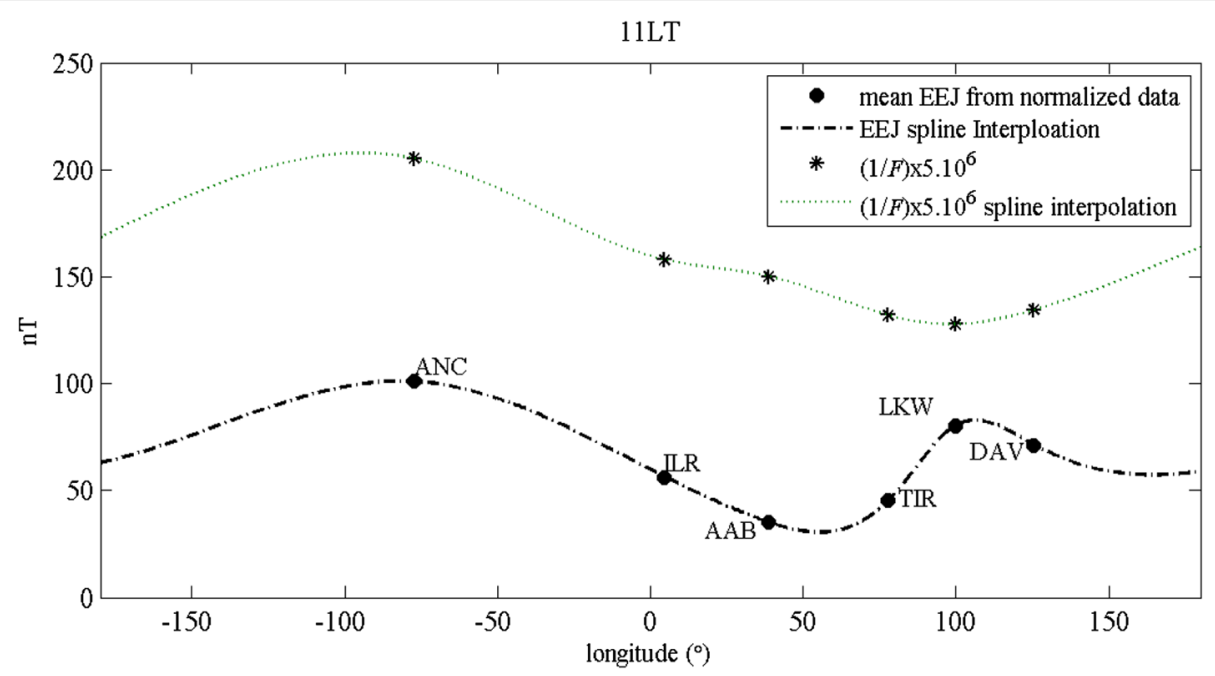

Fig. 5 Longitude dependence of the magnetic component of EEJ at $1100 \mathrm{LT}$ and the inverse of the main field (1/F)

the ionospheric regular dynamo, and in turn depends on the local magnitude of the main field through the ionosphere conductivity and is given by Ohm's law in the low-latitude ionosphere. Both Pedersen and Hall conductivities depend on the intensity of the main field through the gyrofrequency, and consequently, the longitudinal inequalities in the main field $(F)$ are expected to induce longitudinal variation in the EEJ intensity (Doumouya et al. 2003; Hamid et al. 2013). We further checked this by plotting the inverse main intensity field $(1 / F)$ at the dip equator, multiplied by an arbitrary factor, $5 \times 10^{6}$, in order to reach the same amplitude range as EEJ. It is shown that the longitude variations of EEJ roughly follow variations of the inversed main field strength along the dip equator with some discrepancy in the Indian and Southeast Asian sectors. Our result is similar to the one obtained by Doumouya and Cohen (2004). On the other hand, Alken and Maus (2007) showed similar wave structures between their model of EEJ longitudinal profile with the meridional diurnal winds from the GSWM-02 wind model (Hagan and Forbes 2002) during both March and September equinoxes. An independent future study will be conducted to investigate the factors that contributed to the dependence of EEJ longitudinal structure.

The longitudinal function of EEJ, $I_{11}(\lambda)$, is then obtained using the following formula given by Doumouya et al. (1998):

$$
I 11(\lambda)=\frac{\mathrm{EEJ}_{11}(\lambda)}{0.4_{\operatorname{arctg}}\left(\frac{a}{h}\right)}
$$

where $a$ and $h$ are the half width and height of EEJ, adopted as 330 and $105 \mathrm{~km}$, respectively.
The following expression, corresponding to the fourthdegree current distribution, is then used to compute the EEJ magnetic signature in $\mathrm{nT}$ :

$$
\begin{aligned}
\operatorname{EEJ}(t, \lambda)= & 0.2 \frac{I_{0}}{a^{4}}\left[\left(a^{2}-X_{\mathrm{S}}^{2}\right)^{2}+\left(2 a^{2}-6 X_{\mathrm{S}}^{2}\right) h^{2}+h^{4}\right]\left(\arctan R_{\mathrm{B}}-\arctan R_{\mathrm{A}}\right) \\
& +0.2 \frac{I_{0}}{a^{4}}\left[2\left(a^{2}-X_{\mathrm{S}}^{2}\right) X_{\mathrm{S}} h+2 X_{\mathrm{S}} h^{3}\right]\left[\ln \left(1+R_{\mathrm{B}}^{2}\right)-\ln \left(1+R_{\mathrm{A}}^{2}\right)\right] \\
& +0.2 \frac{I_{0}}{a^{4}} \frac{h^{4}}{3}\left(R_{\mathrm{B}}^{3}-R_{\mathrm{A}}^{3}\right)-0.4 \frac{I_{0}}{a^{4}} X_{\mathrm{S}} h^{3}\left(R_{\mathrm{B}}^{2}-R_{\mathrm{A}}^{2}\right) \\
& -0.2 \frac{I_{0}}{a^{4}}\left[\left(2 a^{2}-6 X_{\mathrm{S}}^{2}\right) h^{2}+h^{4}\right]\left(R_{\mathrm{B}}-R_{\mathrm{A}}\right)
\end{aligned}
$$

where $X_{\mathrm{S}}=x s-c=0 ; \quad R_{\mathrm{A}}=\frac{X_{\mathrm{S}}-a}{h} ; R_{\mathrm{B}}=\frac{X_{\mathrm{S}}+a}{h}$.

This equation is adopted from Doumouya et al. (2003) with a modification where the distance between stations located at positions $x s$ and $c$ (position of EEJ center), symbolized as $X_{\mathrm{s}}$, is assigned to 0 due to the applied normalization technique. $I_{0}$ (current intensity at the EEJ center) is in $\mathrm{A} / \mathrm{m}$ while $\mathrm{EEJ}$ is in $\mathrm{nT}$. In the empirical model developed, $I_{0}$ is represented by the time- and longitude-varying current intensity, $I(t, \lambda)$, discussed earlier. The simplified expression is shown below.

$$
\begin{aligned}
& \operatorname{EEJ}(t, \lambda)=0.4 \frac{I(t, \lambda)}{a^{4}}\left[\left(a^{2}+h^{2}\right)^{2} \arctan \left(\frac{a}{h}\right)+\frac{a^{3} h}{3}-2 a^{3} h-a h^{3}\right] \\
& =34.8713 \times \frac{\mathrm{EEJ}_{11}(\lambda)}{28.94} \exp \left(-\frac{(t-11)^{2}}{16}\right) \\
& =1.205 \mathrm{EEJ}_{11}(\lambda) \exp \left(-\frac{(t-11)^{2}}{16}\right) .
\end{aligned}
$$

The comparison between measured and modeled EEJ components between $0900 \mathrm{LT}$ and $1500 \mathrm{LT}$ for available dip equator stations are presented in Fig. 6, where it is shown that the patterns of measured and modeled noontime EEJ are quite similar, with the greatest difference in 


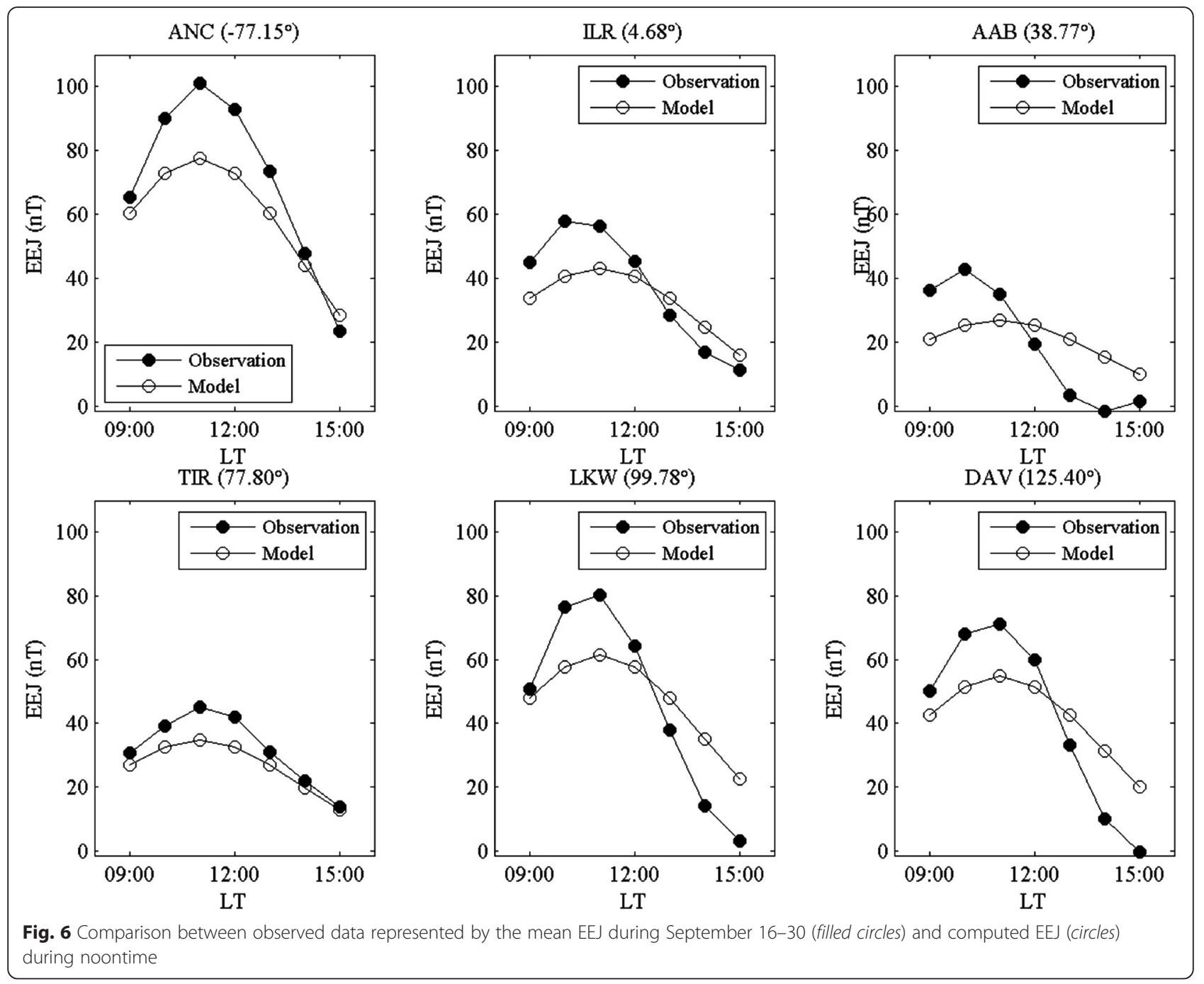

magnitudes at about $25 \mathrm{nT}$ at the South American sector. A good agreement can be observed in the Indian sector. This is proven by the root-mean-square deviation (RMSD) value calculated between the measured and model EEJ magnetic components for each longitude sector, as shown in Table 2. It can be seen that the RMSD for the Indian sector is the lowest among others, while that for the Southeast Asian sector is the highest. These quantitative values agreed with the plots in Fig. 6, in

Table 2 Root-mean-square deviation (RMSD) between measured data and model output of EEJ magnetic component

\begin{tabular}{llr}
\hline Region & Station code & RMSD \\
\hline South America & ANC & 14.64 \\
African & ILR & 10.22 \\
& AAB & 13.70 \\
India & TIR & 6.31 \\
Southeast Asia & LKW & 15.47 \\
& DAV & 15.34 \\
\hline
\end{tabular}

which the decreasing trend in EEJ strength after 1300 LT appears to be different from measured and modeled EEJ in the African and the Southeast Asian sectors, consequently resulting in the high RMSD at these sectors. As for the South American sector, the high RMSD value could be influenced by the large misfit between model and measured EEJ during $1100 \mathrm{LT}$ at the longitude of Ancon (ANC).

We further examined the longitudinal profile of EEJ magnetic signature derived from the model (circles) and compared it with the observations (circles filled), as in Fig. 7. Two prominent enhancements were observed; the first one was at the South American sector and the second one was west of Southeast Asian sector at around $100^{\circ} \mathrm{E}$. For each local time from 0900 to 1500 , the longitudinal profile of EEJ showed that this current was strongest in the South American sector and weakest in the African sector, unlike the observation data where EEJ was the smallest in the Indian sector during 0900 and $1000 \mathrm{LT}$, but shifted to the East African sector 


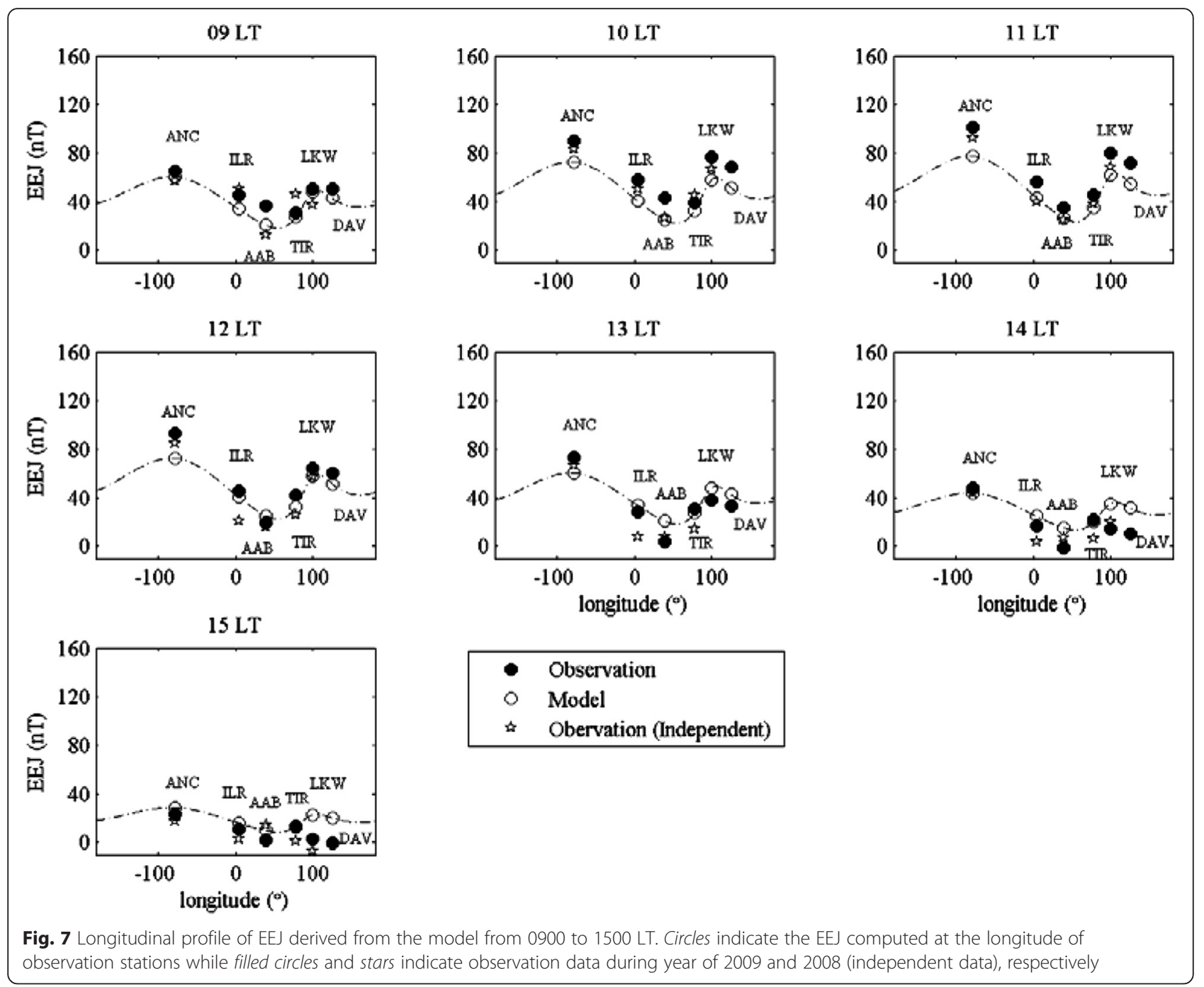

during 1100 to 1400 LT. Additionally, we added the mean of the observation data during the same period (fall season) of 2008 (solar minimum) from all stations, except DAV at Southeast Asia (due to the absence of data). These data, represented by the star mark, could be used as an independent measurement to validate the model output. The model output was found to be in good agreement with observation data, from both 2008 and 2009, especially during 1100 and 1200 LT. This validated the longitudinal profile of the EEJ model output, particularly at local times.

This model provides an improved version of the empirical model proposed by Doumouya et al. (2003). The data used are from the end of a long, deep, solar minimum (2009), in which the conductivity may be lower than the normal solar minimum (as EUV was very low during the deep minimum). Consequently, the magnitude of EEJ from this model could be lower. However, it may not affect the longitudinal variation, which depends mainly on B and the wind; neither is much influenced by the deep minimum. Two novel features of this current model are the normalization of observation data to the dip equator and the elimination of Sq contribution at the dip equator, which are limited in most of previous studies. The EEJ longitudinal profile obtained is similar to the one shown by Doumouya and Cohen (2004), with some discrepancy appearing in the African sector, where our result shows a decreasing trend in this sector while their result shows a small increasing trend. This could be caused by the location of the observatory station used. Our second station in this region $(\mathrm{AAB}$, $38.77^{\circ} \mathrm{E}$ ) is located nearest to the edge of the East African sector, compared to their station (MOK, 13:48 $\mathrm{E}$ ). Therefore, a further study is suggested to include a dense longitudinal chain of stations across the sector. Other than that, their study used data from single stations to represent EEJ at the dip equator, and this might also cause the difference observed. Thus, the result 
obtained in this study is more precise, as the EEJ was successfully calculated after the Sq effect and uncertainty due to latitudinal variation of observation data have been removed. A better comparison can be made with the study by Alken and Maus (2007) where a clean EEJ signal was obtained using satellite data. It is expected that both satellite and ground-based plots of EEJ longitudinal profiles should highlight the prominent features. The EEJ profile from their study shows a strong enhancement at longitudes of $90^{\circ} \mathrm{E}$ and $90^{\circ} \mathrm{W}$, which corresponds to the enhancement at the Southeast Asian and the South American sectors in our longitudinal profile of EEJ magnetic effect. However, the other two enhancements at longitude of about $0^{\circ}$ and $180^{\circ}$ in their study are unattainable by our model. This is due to the fact that our model is based on observation data controlled by the distribution of a ground-based magnetometer, which explains the differences observed, particularly in the region of the Atlantic and Pacific Oceans.

\section{Conclusion}

An empirical model of the EEJ magnetic signature, including local time and longitudinal dependence, was constructed on the basis of simultaneous observations recorded from 12 magnetometer stations located in six different longitude sectors after the normalization of observation data to the dip equator. The analysis showed that the EEJ component is strongest in the South American sector, regardless of local time and weakest in the Indian sector during 0900 and 1000 LT, but shifted to the African sector during the period 1100 to 1400 LT. The result showed that the EEJ component derived from the model presented a pattern similar to the measured EEJ from ground magnetic data mainly before $1300 \mathrm{LT}$. In summary, the improved empirical model in this study has successfully reproduced the EEJ components on a global scale around noontime. In the present study, the EEJ local time profile is assumed to be a simple Gaussian-type profile. Future work is necessary to improve this profile as well as to account for the longitudinal shift of the minimum EEJ at different local times and to explain the cause of the longitudinal profile obtained.

\section{Competing interests}

The authors declare that they have no competing interests.

\section{Authors' contributions}

NSAH has analyzed the data, carried out the studies, participated in the sequence alignment, and drafted the manuscript. $\mathrm{HL}$ participated in the data analysis, sequence alignment, drafting, and revision of the manuscript. TU contributed in the processing of the EE-index data and revised the manuscript. AY contributed in the acquisition of the data and revised the manuscript. All authors read and approved the final manuscript.

\section{Acknowledgements}

The authors thank all the member of the MAGDAS project for their cooperation and contribution to this study. Financial support was provided by the Universiti Kebangsaan Malaysia and Ministry of Education, Malaysia, using grants GGPM2015-020 and FRGS/1/2015/ST02/UKM/02/1. H. Liu is supported by JSPS KAKENHI Grant Numbers 15K05301, 15H02135, and 15H03733. T. Uozumi and A. Yoshikawa were supported in part by JSPS Core-to-Core Program (B. Asia-Africa Science Platforms), Formation of Preliminary Center for Capacity Building for Space Weather Research.

\section{Author details}

${ }^{1}$ School of Applied Physics, Faculty of Science and Technology, Universiti Kebangsaan Malaysia, 43600 UKM Bangi, Selangor, Malaysia. ${ }^{2}$ Department of Earth and Planetary Science, Faculty of Science, Kyushu University, 744 Motooka, Nishi-ku, Fukuoka 819-0395, Japan. International Center for Space Weather Science and Education (ICSWSE), Kyushu University, 744, Motooka, Nishi-ku, Fukuoka 819-0395, Japan.

Received: 6 July 2015 Accepted: 15 December 2015

Published online: 29 December 2015

References

Alken P, Maus S (2007) Spatio-temporal characterization of the equatorial electrojet from CHAMP, Ørsted, and SAC-C satellite magnetic measurements. J Geophys Res 112:A09305. doi:10.1029/2007JA012524

Chandrasekhar N, Arora K, Nagarajan N (2014) Evidence of short spatial variability of the equatorial electrojet at close longitudinal separation. Earth Planets Space 66:110

Chapman S (1951) The equatorial electrojet as detected from the abnormal electric current distributions above Huancayo, Peru, and elsewhere. Arch Meteorol Geophys Bioclimatol A4:368-390

Doumouya V, Cohen Y (2004) Improving and testing the empirical equatorial electrojet model with CHAMP satellite data. Ann Geophys 22:3323-3333

Doumouya V, Cohen Y, Arora BR, Yumoto K (2003) Local time and longitude dependence of the equatorial electrojet magnetic effects. J Atmos Terr Phys 65:1265-1282

Doumouya V, Vassal J, Cohen Y, Fambitakoye O, Menvielle M (1998) Equatorial electrojet at African longitudes: first results from magnetic measurements. Annales Geophysicae, European Geosciences Union 16(6):658-666.

Fambitakoye, Mayaud PN (1976) Equatorial electrojet and regular daily variation SR-1. A determination of the equatorial electrojet parameters. J Atmos Terr Phys 38:1-17

Forbes JM (1981) The equatorial electrojet. Rev Geophys Space Phys 19:469-504 Hagan ME, Forbes JM (2002) Migrating and nonmigrating diurnal tides in the middle and upper atmosphere excited by tropospheric latent heat release. J Geophys Res 107(D24):4754. doi:10.1029/2001JD001236

Hamid NSA, Liu H, Uozumi T, Yumoto K (2013) Equatorial electrojet dependence on solar activity in the Southeast Asia sector. Antarct Record 57(3):329-337

Hamid NSA, Liu H, Uozumi T, Yumoto K, Veenadhari B, Yoshikawa A, Sanchez JA (2014) Relationship between the equatorial electrojet and global Sq currents at the dip equator region. Earth Planets Space 66:146

Onwumechili CA (1997) The equatorial electrojet. Gordon and Breach Science Publishers, Amsterdam, The Netherlands

Onwumechili CA, Ezema PO (1992) Latitudinal and vertical parameters of the equatorial electrojet from an autonomous data set. J Atmos Terr Phys 54(11): $1535-1544$

Sabaka TJ, Olsen N, Purucker ME (2004) Extending comprehensive models of the Earth's magnetic field with Ørsted and CHAMP data. Geophys J Int 159:521547

Shume EB, Denardini CM, Paula ER, Trivedi NB (2010) Variabilities of the equatorial electrojet in Brazil and Peru. J Geophys Res 115:A06306

Stening RJ (1995) What drives the equatorial electrojet? J Atmos Solar-Terr Phys 57:1117-1128

Uozumi T, Yumoto K, Kitamura K, Abe S, Kakinami Y, Shinohara M, Yoshikawa A, Kawano H, Ueno T, Tokunaga T, McNamara D, Ishituka JK, Dutra SLG, Damtie B, Doumbia V, Obrou O, Rabiu AB, Adimula IA, Othman M, Fairos M, Otadoy RES, MAGDAS Group (2008) A new index to monitor temporal and long-term variations of the equatorial electrojet by MAGDAS/CPMN real-time data: EEIndex. Earth Planets Space 60:785-790

Yumoto K, the MAGDAS Group (2007) Space weather activities at SERC for $\mathrm{HY}$ : MAGDAS. Bull Astronomic Soc India 35:511-522 